\title{
ABSTRACT
}

\section{Nanofiltration of Hormone Mimicking Trace Organic Contaminants}

\author{
Submitted to
}

Separation Science and Technology

May 2, 2005

LONG D. NGHIEM ${ }^{1}$, ANDREA I. SCHÄFER ${ }^{1}$, AND MENACHEM ELIMELECH ${ }^{2, *}$

${ }^{1}$ Environmental Engineering

University of Wollongong, NSW 2522, Australia

${ }^{2}$ Department of Chemical Engineering

Environmental Engineering Program Yale University

New Haven, Connecticut 06520-8286, USA
* Corresponding author: Menachem Elimelech

Email: menachem.elimelech@yale.edu, Phone: +1 (203) 432-2789.
The removal mechanisms of three hormone mimicking organic compounds by nanofiltration (NF) membranes have been examined. Two NF membranes having different pore size were used in laboratory-scale nanofiltration experiments with feed solutions spiked with a hormone mimicking compound - nonylphenol, tert-butyl phenol, or bisphenol A. Retention of the compounds was determined at various solution chemistries, namely aqueous solution $\mathrm{pH}$, ionic strength, and presence of natural organic matter. The nanofiltration behavior of the selected hormone mimicking presence of natural organic matter. The nanofiltration behavior of the selected hormone mimicking
compounds appears similar to that of natural hormones as reported in our previous work. While the solution $\mathrm{pH}$ can dramatically influence the retention of hormone mimicking compounds by a loose $\mathrm{NF}$ membrane, ionic strength does not affect the nanofiltration of such contaminants. However, in the presence of natural organic matter in the feed solution, ionic strength appears to play a significant role in solute-solute and solute-membrane interactions, resulting in increased retention due to partitioning of the hormone mimicking compounds onto organic matter at a higher ionic strength.

Key words: Endocrine disrupting chemicals; Bisphenol A; Nonylphenol; Nanofiltration; Trace organic contaminants.

\section{INTRODUCTION}

The presence of hormone mimicking compounds in secondary wastewater effluents and in freshwater bodies has caused great concern over their potentially adverse health impact on humans and wildlife. Most of these compounds are of significant industrial importance. Prominent amongst them are alkylphenol ethoxylates (APEs) and bisphenol A (BPA). APEs are a group of nonionic surfactants extensively used as industrial cleaning and wetting agents, emulsifiers, and domestic detergents. Despite a significant environmental concern over the use and disposal of these chemicals, the demand for APEs grows steadily with a current annual production estimated to be chemicals, the demand for APEs grows steadily with a current annual production estimated to be
approximately 500,000 tons ${ }^{[1]}$. Similarly, BPA is extensively employed in the production of epoxy resins and polycarbonates. The annual BPA production is reported to be in excess of 1 million tons [2].

APEs together with some BPA enter the aquatic environment primarily as components of industrial and domestic wastewater. During the biological wastewater treatment process, APEs degrade into a complex mixture of several biorefractory metabolites, mostly consisting of short chain alkylphenols such as nonylphenol and octylphenol ${ }^{[3]}$. Unfortunately, these metabolites are often more persistent, toxic, and bio-accumulative than their parent compounds. Swiss researchers, who followed the transformation of APEs in 11 sewage treatment plants in Switzerland, reported that up to $40 \%$ of the initial APEs load could reach the aquatic environment via secondary effluent, mostly in the initial APEs load could reach the aquatic environment via secondary effluent, mostly in
alkylphenol forms ${ }^{[3,4]}$. This is supported by numerous studies conducted in several other countries, consistently demonstrating the ubiquitous and widespread occurrence of hormone mimicking compounds in secondary wastewater effluents and receiving waters ${ }^{[5,6]}$. Alkylphenols and BPA are commonly detected in secondary effluent and sewage impacted water bodies through out the world at concentrations within the lower microgram per liter ( $\mathrm{ppb}$ ) range, although concentrations up to several hundreds microgram per liter have been also reported ${ }^{[5,}$ Although endocrine disrupting potency and other chronic effects of alkyl phenols and BPA are very
well documented in the literature ${ }^{[1,9,10]}$, there is a lack of information concerning the removal of hormone mimicking compounds prior to wastewater effluent discharge and particularly during water recycling, which has been strongly endorsed by the water industry as a sound approach to 
combat water shortage ${ }^{[11,12]}$. Nanofiltration appears to be a potential technology to address the water recycling issue, in particular when trace contaminants are a concern. The effectiveness of NF membranes in removing low molecular weight organics such as pesticides has been recently demonstrated ${ }^{[13-16]}$. Promising retention values of hormone mimicking compounds such as nonylphenol and BPA have also been reported in several studies ${ }^{[17,18]}$. However, the removal mechanisms and particularly the influence of solution chemistry on the retention of hormone mimicking compounds by NF membranes remain poorly understood.

The purpose of this study is to elucidate the removal mechanisms of hormone mimicking compounds by NF membranes and to examine the influence of solution chemistry, namely $\mathrm{pH}$, ionic strength, and organic matter content on the separation process. Experiments were carried out with two NF membranes whose pore sizes have been previously characterized. Retention was related to the membrane characteristics and the compound physicochemical properties. Solution chemistry effects were investigated by considering the resulting behavior of hormone mimicking compounds and their interactions with the membrane and the natural organic matter of the feed solution during the nanofiltration process.

\section{MATERIALS AND METHODS}

\section{NF Membranes}

Two commercially available NF membranes, denoted NF-270 and NF-90 (FilmTec Corp., Minneapolis, MN), were used in this investigation. The membranes were received as flat sheets and were stored in deionized (DI) water (NanoPure II, Dubuque, IA) at $4{ }^{\circ} \mathrm{C}$. According to the manufacturer, both membranes are polyamide thin-film composite with a microporous polysulfone supporting layer. Some key properties of these membranes have been described elsewhere ${ }^{[22,24-26]}$.

\section{Contact Angle Measurement}

The captive bubble method was employed to measure the contact angle of the clean membranes. Measurements were performed with an NRL contact angle goniometer (Rame Hart, Mountain Lakes, NJ). Details on the measurement technique are described elsewhere ${ }^{[19]}$.

\section{Hormone Mimicking Organic Compounds}

Three hormone mimicking compounds, namely, nonylphenol (NP), tert-butylphenol (TBP), and bisphenol A (BPA) were selected for this investigation (Figure 1). These compounds are amongst the most prominent emerging wastewater contaminants that have to date been identified. As seen in Figure 1, a characteristic feature of these compounds is the presence of phenolic functional groups with a hydrophobic alkyl chain. Stock solutions $(1 \mathrm{~g} / \mathrm{L})$ of all three compounds were prepared in pure methanol. The stock solutions were stored at $<4^{\circ} \mathrm{C}$ and were used within 1 month.

\section{[FIGURE 1]}

\section{NF Membrane Bench-scale Unit}

A laboratory-scale, crossflow membrane filtration test unit was used in this study. The unit utilizes a Hydra-Cell pump (Wanner Engineering Inc., Minneapolis, MN) capable of providing pressures up to $68 \mathrm{bar}(1000 \mathrm{psi})$ and a crossflow of 4.2 liters per minute. The temperature of the feed solution was controlled using a refrigerated circulator (Neslab RTE 111). A duplicate plate-and frame membrane cells us $7.7 \mathrm{~cm} \times 3.0 \mathrm{~cm}$. The permeate flow rate was monitored by a digital flow meter connected to a PC and crossflow rate was monitored by a rotameter. All test unit parts in contact with the solution are made of stainless steel or Teflon to minimize adsorption of the organic compounds.

\section{Membrane Filtration Protocol}

Prior to each experiment, the membrane was stabilized at 12 bar (176.4 psi) using deionized (DI) water for at least 16 hours until the permeate flux attained a constant value. The feed reservoir temperature was kept at $20 \pm 0.1^{\circ} \mathrm{C}$ throughout the experiment. After stabilizing the membrane, the feed reservoir was emptied and 4 liters of DI water was introduced to the feed reservoir. The cross feed reservoir was emptied and 4 liters of DI water was introduced to the feed reservoir. The cross
flow velocity and the permeate flux were adjusted to $30.4 \mathrm{~cm} / \mathrm{s}$ and $15 \mu \mathrm{m} / \mathrm{s}\left(54 \mathrm{~L} / \mathrm{m}^{2} \mathrm{~h}\right.$ or $\left.32.4 \mathrm{gfd}\right)$, respectively. The membrane permeability was then determined. Test compounds were spiked into the feed reservoir to make up a concentration of $500 \mu \mathrm{g} / \mathrm{L}$. Unless otherwise stated, the permeate and retentate were recirculated back to the feed reservoir. Feed and permeate samples (approximately $2 \mathrm{~mL}$ each) were taken for analysis at specified time intervals.

Suwannee River natural organic matter (SRNOM) supplied by the International Humic Substances Society (St. Paul, MN) was used to represent natural organic matter (NOM) in some experiments. In such experiments, the NOM concentration in the feed solution was $10 \mathrm{mg} / \mathrm{L}$. The NOM concentration was confirmed by measuring total organic carbon (TOC) of the feed solution. SRNOM was selected because of its high concentration of dissolved organic carbon and low SRNOM was selected because of its high concentration of dissolved organic carbon and low
concentration of inorganic salt (ash content of $7 \%$ ). Contribution of this ash to the solution ionic strength is assumed to be negligible. When necessary, certified grade $\mathrm{NaCl}$ and $\mathrm{NaOH}$ or $\mathrm{HCl}$ (Fisher Scientific, Pittsburgh, PA) were added to the feed solution to adjust the ionic strength and $\mathrm{pH}$, respectively.

Membrane calcium and sodium retentions were obtained by challenging the membranes with a single salt solution (i.e. $\mathrm{CaCl}_{2}$ or $\mathrm{NaCl}$ ). Calcium and sodium concentrations of the feed solution were $1 \mathrm{mM}$ and $10 \mathrm{mM}$, respectively. The applied pressure was $5 \mathrm{bar}$ and the experiments were conducted at $\mathrm{pH} 6$

\section{Analytical Methods}

A Shimadzu high-performance liquid chromatography (HPLC) system was used to analyze the three hormone mimicking compounds: nonylphenol, bisphenol A, and tert-butylphenol. The system comprised an autosampler (model SIL-10ADvp), a solvent delivery system, and a UV-Vis detector (SPD-10AVvp). The solvent delivery system included two HPLC pumps, a degaser, and a gradient mixer. A reversed phase column (Discovery ${ }^{\circledR} \mathrm{C} 18$ with pore size, length, and diameter of $5 \mu \mathrm{m}$, $250 \mathrm{~mm}$, and $4.6 \mathrm{~mm}$, respectively) supplied by Supelco was used. The UV wavelength was set $280 \mathrm{~nm}$. DI water and ace $280 \mathrm{~nm}$. DI water and acetonitrile (ACN) - delivered at a constant flow rate of $1 \mathrm{~mL} / \mathrm{mir}$ used as the mobile phase for gradient elution. The gradient program of the mobile phase was adapted from a method reported by Ying and Kookana ${ }^{20]}: 30 \% \mathrm{ACN}$ and $70 \%$ water at $0 \mathrm{~min}, 80 \%$ $\mathrm{ACN}$ and $20 \%$ water from 12 to $24 \mathrm{~min}, 100 \% \mathrm{ACN}$ at $24 \mathrm{~min}$, and $30 \% \mathrm{ACN}$ and $70 \%$ water at 30 min. Each analysis lasted $35 \mathrm{~min}$ and the injection volume was $50 \mu \mathrm{L}$. The detection limit was approximately $20 \mu \mathrm{g} / \mathrm{L}$ for these contaminants. Analysis was conducted immediately following the nanofiltration experiments.

TOC was measured with a TOC- $\mathrm{V}_{\mathrm{CSH}}$ analyzer (Shimadzu Corporation, Kyoto, Japan). A Perkin Elmer Optima 3000 ICP-AES Instrument was used to measure calcium and sodium concentrations. Samples were diluted 1:1 with $5 \%$ analytical grade nitric acid prior to analysis.

\section{RESULTS AND DISCUSSIONS}


Nghiem, D.L. ; Schäfer, A.I. ; Elimelech, M. (2005) Nanofiltration of hormone mimicking trace organic contaminants,

\section{Membrane Characteristics}

Results of contact angle measurements indicate that both membranes are relatively hydrophobic (Table 1). The NF-270 membrane has a very thin semi-aromatic piperazine-based polyamide active layer ${ }^{[21]}$, which results in a relatively smooth surface ${ }^{[22,23]}$. This is possibly the reason for the excellent performance of the membrane, specifically high water permeability and organic matter retention [24]. On the of retention a result of these subtle differences in the polymer composition and morphology of the active layers, the NF-90 membrane is less hydrophobic (represented by a lower contact angle) than the NF-270 membrane, as shown in Table 1.

[TABLE 1]

Average pore radii and zeta potentials of both membranes have been determined in our previous studies ${ }^{[25,26]}$. Results from these studies reveal that the NF-270 is a relatively loose NF membrane while the NF-90 is a tight NF membrane. Both membranes have a slightly positive zeta potential below $\mathrm{pH} 3.5$ and are negatively charged above this $\mathrm{pH}^{[26]}$. While $\mathrm{Ca}^{2+}$ retention by the NF-90 membrane is considerably higher than that of $\mathrm{Na}^{+}$, the NF-270 membrane shows a simila selectivity for the divalent $\left(\mathrm{Ca}^{2+}\right)$ and monovalent $\left(\mathrm{Na}^{+}\right)$ions (Table 1$)$. In the latter case, the trend is not in accord with the size of the hydrated ions. When Donnan exclusion is the predominant mechanism for salt retention, counterions have a higher concentration in the membrane pores than in the bulk solution because of electrostatic attraction between the negatively charged membrane and the oppositely charged counterions ${ }^{[27]}$. Consequently, counterions with a higher valence are less retained by the membrane despite their larger hydrated radius. This behavior is typical for a loose, negatively charged NF membrane ${ }^{[27,28]}$. In our case, it appears that the NF-270 membrane exhibits certain Donnan exclusion behavior, with electrostatic interactions playing an important role in salt retention. On the other hand, the salt retention mechanism by the NF-90 appears to be predominantly governed by steric (size) exclusion.

\section{Physicochemical Properties of Hormone Mimicking Compounds}

Numerous studies have demonstrated the capacity of alkylphenols and bisphenol A to interact with hormone receptors in similar and sometimes precisely the same mechanisms as natural hormone $[10,29,30]$. Physicochemical properties of the selected hormone mimicking compounds in this study are also quite similar to those of natural hormones. They all have phenolic groups with a comparable $\mathrm{pK}_{\mathrm{a}}$ value, in a range of $10.1-10.3$. Below $\mathrm{pH} 10$, these compounds are neutral in charge, and interactions between their polar centers and the membrane fixed charge groups are expected to be negligible, given their relatively low dipole moments ${ }^{[31]}$ (Table 2).

[TABLE 2]

The octanol-water partitioning coefficients $\left(\log \mathrm{K}_{\mathrm{ow}}\right.$ ) of these compounds vary from moderately high (BPA and TBP) to very high $\log \mathrm{K}_{\mathrm{ow}}$ (NP), corresponding to relatively low to very low solubility in water, as can be seen in Table 2 . This indicates that they readily adsorb to hydrophobic materials. However, given the presence of the proton donor and acceptor functional groups of the compounds, hydrogen bonding can also play an important role in governing the interaction between these hormone mimicking compounds and the membrane polymers ${ }^{[25,324}$.

\section{Nanofiltration of Hormone Mimicking Compounds}

Nanofiltration of hormone mimicking compounds is quite similar to that of natural hormones as we reported before ${ }^{[25]}$. The compounds investigated in this study are undissociated at the $\mathrm{pH}$ of the reported before
experiments ( $\mathrm{pH} 6$ ). As we delineated previously, interactions between the compounds polar centers and the membrane surface are expected to be minimal. Consequently, removal is predominantly governed by steric (size) exclusion and adsorption.

Due to adsorption of the hormone mimicking compounds to the membrane polymer, their concentrations in the feed decrease and then stabilize as an equilibrium is attained (Figures 2-4). Nonylphenol (NP) adsorbed strongly to both membranes and the feed concentration was completely depleted after approximately 4 hours (Figure 4 ). No NP was detected in the permeate samples and therefore only feed concentrations are presented in Figure 4. This behavior is attributed to the compounds very high $\log \mathrm{K}_{\mathrm{ow}}$ value (Table 1), which results in a strong hydrophobic interaction with the membrane polymer. For all compounds in this study, the partitioning process reached equilibrium in a much shorter time than that of natural hormones as we reported previously ${ }^{[25]}$. It should be emphasized, however, that the initial concentrations of the hormone mimicking compounds used in these experiments $(500 \mu \mathrm{g} / \mathrm{L})$ were about 3 orders of magnitude higher than those with the natural hormones in our earlier work $(100 \mathrm{ng} / \mathrm{L})^{[25]}$

[FIGURE 2]

[FIGURE 3]

[FIGURE 4]

Assuming purely steric solute-membrane interactions and negligible polar interference, the observed retention of inert organics with a given radius can be predicted for the NF-270 and NF-90 membranes based on the pore transport model described in our previous study ${ }^{[25]}$. Figure 5 shows membranes based on the pore transport model described in our previous study the observed retention of BPA and TBP taken at the end of the filtration experiments (ca. 30 hours)
when a partitioning equilibrium has been reached. The predicted observed retention of inert organics and hormone retentions obtained from our previous study are also included in this figure

\section{[FIGURE 5]}

Retention of hormone mimicking compounds is lower than the predicted value based purely on a steric (or size) exclusion mechanism (Figure 5). This is attributed to the partitioning (or adsorption) and subsequent diffusion of hormone mimicking compounds in the membrane polymer phase. However, steric exclusion remains the predominant mechanism responsible for the retention of hormone mimicking compounds. Because BPA and TBP have smaller molecular weights (or hormone mimicking compounds. Because BPA and TBP have smaller molecular weights (or
molecular sizes) than the steroid hormones, their retentions by the NF-270 membrane are molecular sizes) than the steroid hormones, their retentions by the NF-270 membrane are
considerably lower (Figure 5a). Similarly, although lower than the predicted value, BPA and TBP retentions by the tight NF-90 membrane remain quite high, indicating a central role of steric exclusion in the separation of hormone mimicking compounds (Figure $5 b$ ).

\section{Influence of Solution pH on Retention}

Since the pKa of BPA is 10.1 , it transforms from a neutral protonated species to a negatively charged deprotonated species as $\mathrm{pH}$ rises to $\mathrm{pH} 11$. Consequently, the retention mechanism at $\mathrm{pH}$ 11 can be significantly different. As seen in Figure 6, BPA retention by the loose NF-270 11 can be significantly different. As seen in Figure 6, BPA retention by the loose NF-270
membrane at $\mathrm{pH} 11$ is predominantly governed by electrostatic (charge) exclusion [33]. Due to membrane at $\mathrm{pH} 11$ is predominantly governed by electrostatic (charge) exclusion ${ }^{[33]}$. Due to
electrostatic repulsion between the negatively charged BPA and the negative membrane surface, no electrostatic repulsion between the negatively charged BPA and the negative membrane surface, no
adsorption of BPA to the membrane is observed. Retention is almost complete and independent of filtration time. This is consistent with our previous discussion that the loose NF-270 membrane exhibits a typical Donnan exclusion behavior and charge interaction can play an important role in the separation of negatively charged solutes. The results indicate that a significant influence of solution $\mathrm{pH}$ on the retention of hormone mimicking compounds is expected in the vicinity of the $\mathrm{pK}_{\mathrm{a}}$ value due to the compound speciation. 
Nghiem, D.L. ; Schäfer, A.I. ; Elimelech, M. (2005) Nanofiltration of hormone mimicking trace organic contaminants,

\section{[FIGURE 6]}

\section{Effect of Ionic Strength on Retention}

Although ionic strength can strongly influence the electrostatic interaction between fixed charge groups of organic macromolecules and hence their conformation ${ }^{[34-36]}$, its effect on the size and shape of small organic molecules such as the hormone mimicking compounds used in this study is expected to be negligible. However, because ionic strength can inflence electrostatic intera expected to be negligible between the membrane cross-linked polymer network can either expand or shrink in response to variations in solution ionic strength. Consequently, this may induce changes in the membrane pore size and thus influence retention characteristics.

To examine this effect, retention experiments were conducted in DI water and in $50 \mathrm{mM}$ (or 2922 $\mathrm{mg} / \mathrm{L}$ ) ionic strength solution. Applied pressure was adjusted to achieve the same water flux and the solution $\mathrm{pH}$ was kept constant at $\mathrm{pH}$ 6. As seen in Figure 7, no apparent influence of ionic strength on the partitioning of BPA and TBP to the NF-270 membrane was observed. The retention behaviors of BPA and TBP in DI water and in a high ionic strength solution by the NF-270 membrane were almost identical. Results reported here suggest that, at the conditions examined me contaminants. However, it is important to note that ionic strength can still influence the charge screening of membrane functional groups and, hence, the retention of charged organic solutes ${ }^{[35]}$.

\section{[FIGURE 7]}

\section{Retention in Presence of Background Natural Organic Matter}

The influence of organic matter on retention of trace organics by NF membranes is complex and involves intricate combinations of solute-membrane and solute-solute interactions. This is reflected by the relatively large number of studies dealing with this subject ${ }^{[13,37-40]}$, although the results are varied and remain largely inconclusive. Several researchers revealed a small but results varied ant ${ }_{39]}$. . In contrast, Berg et al. reported no increase of pesticide retention by several NF membranes with increasing organic matter concentration. Similarly, Zhang et al. ${ }^{40]}$ showed negligible difference between simazine retention in tap water (no organic matter was detected) and in river water $(\mathrm{COD}$ of $56.2 \mathrm{mg} / \mathrm{L}$ ). Such inconsistency in the literature underscores the need for a fundamental understanding of the interactions among trace organics, bulk organics, and the membrane surface. In this study, we attempt to delineate the effect of organic matter on hormone mimicking compound retention by also taking into consideration the effect of ionic strength.

BPA and TBP retentions by the NF-270 membrane in DI water, a solution containing $10 \mathrm{mg} / \mathrm{L}$ of NOM without any added ionic strength, and a solution containing $10 \mathrm{mg} / \mathrm{L}$ of NOM with an ionic strength $(\mathrm{NaCl})$ of $10 \mathrm{mM}$ are presented in Figure 8 . While the presence of $10 \mathrm{mg} / \mathrm{L}$ NOM in DI strength $(\mathrm{NaCl})$ of $10 \mathrm{mM}$ are presented in Figure 8 . While the presence of $10 \mathrm{mg} / \mathrm{L} \mathrm{NOM}$ in DI
water resulted in no increase in BPA and TBP retentions, there is a small but clear retention water resulted in no increase in BPA and TBP retentions, there is a small but clear retention previous section, ionic strength does not influence the membrane pore size and the partitioning process between trace organics and the membrane polymer. However, ionic strength is known to affect the electrostatic interactions between functional groups of both NOM and the membrane polymer ${ }^{[35]}$, which can possibly influence the NOM-membrane and NOM-trace organic

[FIGURE 8]
Charge shielding and double layer compression neutralize repulsive interactions among the NOM functional groups and also with the membrane negative surface. Therefore, at a sufficiently high ionic strength, NOM macromolecules are not only rigid, compact, and spherocolloidal, but can also adsorb more effectively to the membrane surface ${ }^{[34,35,41]}$. Because NOM retention by the NF-270 membrane (measured as TOC) was approximately $90 \%$ at both low and high ionic strength solutions, a layer of NOM is expected to form on the membrane surface. This layer can become denser at higher ionic strengths due to the redu functional groups. Consequently, physicochemical interactions between NOM and trace organics can be enhanced. An ionic strength increase may also lead to a "salting out" effect ${ }^{[42]}$, which can increase the apparent adsorption capacity of NOM for hydrophobic trace organics such as BPA and TPB to some extent, although the ionic strength used here is rather small for a significant salting out effect. Results reported here suggest the significance of solution ionic strength in influencing NOM-trace organic interactions, which is probably the cause for the ambiguity of literature data regarding the role of background organic matter on trace-organic rejection.

\section{CONCLUSION}

Nanofiltration of hormone mimicking compounds such as alkylphenols and bisphenol A appears similar to that of natural hormones. Adsorption of hormone mimicking compounds to the membrane was the dominant removal mechanism at the initial stage of filtration. At later stages, adsorption and subsequent diffusion of hormone mimicking compounds in the membrane polymer resulted in lower retention than what expected based on a steric (or size) exclusion mechanism alone. Nevertheless, it has been verified that steric exclusion is a central separation mechanism of hormone mimicking compounds by NF membranes.

Results further show that solution $\mathrm{pH}$ can significantly influence hormone mimicking compound retention by the loose NF-270 membrane, as charge exclusion became the dominating retention mechanism. Within the range used in this study, ionic strength did nit hormone mimicking compounds in the absence of organic matter. However ionic strength appeared to play a significant role in influencing NOM-trace organic and NOM-membrane interactions. Consequently, the presence of organic matter in the feed solution in conjunction with an adequate ionic strength can discernibly enhance the retention of hormone mimicking compounds by loose NF membranes.

\section{ACKNOWLEDGMENTS}

We acknowledge the doctoral study support to Long Nghiem from the University of Wollongong. A top-up scholarship from the Australian Institution of Nuclear Science and Engineering (AINSE) is also greatly appreciated. Jonathan Brant at the University of Nevada at Reno is also thanked for contact angle measurements.

\section{REFERENCES}

1. Renner, R., European bans on Surfactants Trigger Tranatlantic Debate. Environmental Science \& Technology. 1997, 31, 316A-320A.

2. Greiner, E. Kaelin, T.; Toki, G. CEH report Bisphenol A; SRI International: 2004.

3. Ahel, M.; Giger, W.; Koch, M., Behaviour of alkylphenol polyethoxylate surfactants in the aquatic environment--I. Occurrence and transformation in sewage treatment. Water Research. 1994, 28, (5), $1131-1142$

4. Ahel, M.; Giger, W.; Schaffner, C., Behaviour of alkylphenol polyethoxylate surfactants in the aquatic environment--II. Occurrence and transformation in rivers. Water Research. 1994, 28, (5), $1143-1152$ 

ethoxylates - A review. Environment International. 2002, 28, (3), 215-226.

6. Kolpin, D. W.; Furlong, E. T.; Meyer, M. T.; Thurman, E. M.; Zaugg, S. D.; Barber, L. B.; Buxton, H. T., Pharmaceuticals, hormones, and other organic wastewater contaminants in U.S. streams, 1999-2000: A national reconnaissance. Environmental Science \& Technology. 2002, 36, (6), 12021221.

7. Solé, M.; Alda, M. J. L. d.; Castillo, M.; Porte, C.; Ladegaard-Pedersen, K.; Barceló, D. Estrogenicity Determination in Sewage Treatment Plants and Surface Waters from the Catalonian Area (NE Spain). Environmental Science \& Technology. 2000, 34, (24), 5076 - 5083. 8. Snyder, S. A.; Keith, T. L.; Verbrugge, D. A.; Snyder, E. M.; Gross, T. S.; Kannan, K.; Giesy, J. P., Analytical Methods for Detection of Selected Estrogenic Compounds in Aqueous Mixtures. Environmental Science \& Techo

9. Staples, C. A.; Dome, P. B.; Klecka, G. M.; Oblock, S. T.; Harris, L. R., A review of the environmental fate, effects, and exposures of bisphenol A. Chemosphere. 1998, 36, (10), 2149-2173. 10. Metzler, M., Endocrine Disrupters Part II. In The Handbook of Environmental Chemistry, SpringerVerlag: Berlin, 2002; Vol. 3, 302.

11. Asano, T., Water from (waste)water - the dependable water resource. Water Science \& Technology. 2002, 45, (8), 23-33.

12. Asano, T.; Levine, A. D., Wastewater reclamation, recycling and reuse: past, present, and future Water Science Technology. 1996, 33, (10-11), 1-13.

13. Berg, P.; Hagmeyer, G.; Gimbel, R., Removal of pesticides and other micropollutants by nanofiltration. Desalination. 1997, 113, (2-3), 205-208.

14. Van der Bruggen, B.; Vandecasteele, C., Removal of pollutants from surface water and groundwater by nanofiltration: overview of possible applications in the drinking water industry. Environmental Pollution. 2003, 122, (3), 435-445.

15. Kiso, Y.; Nishimura, Y.; Kitao, T.; Nishimura, K., Rejection properties of non-phenylic pesticides with nanofiltration membranes. Journal of Membrane Science. 2000, 171, (2), 229-237.

16. Wittmann, E.; Cote, P.; Medici, C.; Leech, J.; Turner, A. G., Treatment of a hard borehole water containing low levels of pesticide by nanofiltration. Desalination. 1998, 119, (1-3), 347-352.

17. Agenson, K. O.; Oh, J.-I.; Urase, T., Retention of a wide variety of organic pollutants by differen nanofiltration/reverse osmosis membranes: controlling parameters of process. Journal of Membrane Science. 2003, 225, (1-2), 91-103.

18. Kimura, K.; Amy, G.; Drewes, J. E.; Heberer, T.; Kim, T.-U.; Watanabe, Y., Rejection of organic micropollutants (disinfection by-products, endocrine discupting compounds, and pharmaceutically

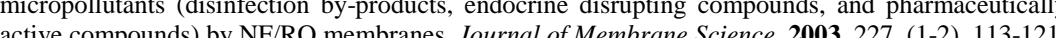

19. Brant, J. A.; Childress, A. E., Assessing short-range membrane-colloid interactions using surface energetics. Journal of Membrane Science. 2002, 203, (1-2), 257-273.

20. Ying, G.-G.; Kookana, R. S., Degradation of five selective endocrine-disrupting chemicals in seawater and marine sediment. Environmental Science \& Technology. 2003, 37, (7), 1256-1260.

21. Freger, V.; Gilron, J.; Belfer, S., TFC polyamide membranes modified by grafting of hydrophilic polymers: an FT-IR/AFM/TEM study. Journal of Membrane Science. 2002, 209, (1), 283-292.

22. Li, Q.; Elimelech, M., Natural organic matter fouling and chemical cleaning of nanofiltration membranes. Water Science and Technology: Water Supply. 2004, 4, (5-6), 245-251.

23. Li, Q.; Elimelech, M., Organic Fouling and Chemical Cleaning of Nanofiltration Membranes Measurements and Mechanisms. Environmental Science \& Technology. 2004, 38, (17), 4683-4693.

24. Manttari, M.; Pekuri, T.; Nyström, M., NF270, a new membrane having promising characteristics and being suitable for treatment of dilute effluents from the paper industry. Journal of Membrane Science. 2004, 242, (1-2), 107-116.

25. Nghiem, D. L.; Schäfer, A. I.; Elimelech, M., Removal of natural hormones by nanofiltration membranes: measurement, modeling, and mechanisms. Environmental Science \& Technology. 2004, 38, 1888-1896.
Nghiem, D. L.; Schäfer, A. I.; Elimelech, M., Pharmaceutical retention mechanisms by nanofiltration membranes. Environmental Science \& Technology. Submitted

27. Peeters, J. M. M.; Boom, J. P.; Mulder, M. H. V.; Strathmann, H., Retention measurements of nanofiltration membranes with electrolyte solutions. Journal of Membrane Science. 1998, 145, (2), 199-209.

28. Seidel, A.; Waypa, J.; Elimelech, M., Role of charge (Donnan) exclusion in removal of arsenic from water by a negatively charged porous nanofiltration membrane. Environmental Enoineering Science. 2001, 18, (2), 105-113.

29. Jobling, S.; Sheahan, D.; Osborne, J. A.; Matthiessen, P.; Sumpter, J. P., Inhibition of testicular Jobling, S.; Sheahan, D.; Osborne, J. A.; Matthiessen, P.; Sumpter, J. P., Inhibition of testicular
growth in rainbow trout (oncorhynchus mykiss) exposed to estrogenic alkylphenolic chemicals. growth in rainbow trout (oncorhynchus mykiss) exposed to estro
Environmental Toxicology and Chemistry. 1996, 15, (2), 194-202.

30. Ashfield, L. A.; Pottinger, T. G.; Sumpter, J. P., Exposure of female juvenile rainbow trout to alkylphenolic compounds results in modifications to growth and ovosomatic index. Environmental Toxicology and Chemistry. 1998, 17, (4), 679-686.

31. Van der Bruggen, B.; Schaep, J.; Wilms, D.; Vandecasteele, C., Influence of molecular size, polarity and charge on the retention of organic molecules by nanofiltration. Journal of Membrane Science. 1999, 156, (1), 29-41.

32. Yamamoto, H.; Liljestrand, H. M.; Shimizu, Y.; Morita, M., Effects of physical-chemical characteristics on the sorption of selected endocrine disruptors by dissolved organic matter characteristics on the sorption of selected endocrine disruptors by diss
surrogates. Environmental Science \& Technology. 2003, 37, (12), 2646 - 2657.

33. Childress, A. E.; Elimelech, M., Relating nanofiltration membrane performance to membrane charge (electrokinetic) characteristics. Environmental Science \& Technology. 2000, 34, (17), 3710-3716.

34. Frank, B. P.; Belfort, G., Polysaccharides and sticky membrane surfaces: critical ionic effects. Journal of Membrane Science. 2003, 212, (1-2), 205-212.

35. Braghetta, A.; Digiano, F. A.; Ball, W. P., Nanofiltraion of natural organic matter: pH and ionic strength effects. Journal of Environmental Engineering. 1997, 123, (7), 628-641.

36. Zander, A. K.; Curry, N. K., Membrane and solution effects on solute rejection and productivity Water Research. 2001, 35, (18), 4426-4434.

37. Nghiem, D. L.; Manis, A.; Soldenhoff, K.; Schäfer, A. I., Estrogenic hormone removal from wastewater using NF/RO membranes. Journal of Membrane Science. 2004, 242, (1-2), 37-45.

38. Devitt, E. C.; Ducellier, F.; Côté, P.; Wiesner, M. R., Effects of Natural Organic Matter and the Raw Water Matrix on the Rejection of Atrazine by pressure-driven Membranes. Water Research. 1998 $32,(9), 2563-2568$.

39. Agbekodo, K. M.; Legube, B.; Dard, S., Atrazine and simazine removal mechanisms by nanofiltration: influence of natural organic matter concentration. Water Research. 1996, 30, (11), 2535-2542.

40. Zhang, Y.; Van der Bruggen, B.; Chen, G. X.; Braeken, L.; Vandecasteele, C., Removal of pesticides by nanofiltration: effect of the water matrix. Separation and Purification Technology.
2004, 38, (2), 163-172.

41. Hong, S.; Elimelech, M., Chemical and physical aspects of natural organic matter (NOM) fouling of nanofiltration membranes. Journal of Membrane Science. 1997, 132, (2), 159-181.

42. Rexwinkel, G.; Heesink, B. B. M.; van Swaaij, W. P. M., Adsorption of halogenated hydrocarbons from aqueous solutions by wetted and nonwetted hydrophobic and hydrophilic sorbents: equilibria. Journal of Chemical and Engineering Data. 1999, 44, (6), 1139-1145.

43. Pallas PrologP/PropKa, 3.1; CompuDrug Chemistry Ltd: Sedona, AZ

44. UNEP SIDS Initial Assessment Report for 10th SIAM: p-tert butyl phenol; 2000.

45. Ahel, M.; Giger, W., Aqueous solubility of alkyl phenols and alkylphenol polyethoxylates. Chemosphere. 1993, 26, (8), 1261-1470.

46. Hyperchem, Release 7.0 for Window, Molecular modeling system, Hypercube Inc, Gainesville, FL. 
Nghiem, D.L. ; Schäfer, A.I. ; Elimelech, M. (2005) Nanofiltration of hormone mimicking trace organic contaminants,

Separation Science \& Technology, 40, 2633-2649.

DOI: $10.1080 / 01496390500283340$

\begin{tabular}{|c|c|c|c|c|c|c|}
\hline Membrane & $\begin{array}{l}\text { Permeability } \\
\left(\mathrm{Lm}^{2} \mathrm{~h}^{-1} \mathrm{bar}^{-1}\right)\end{array}$ & $\begin{array}{l}\text { Contact } \\
\text { angle }\end{array}$ & $\begin{array}{c}\text { Average } \\
\text { roughness a } \\
(\mathrm{nm})\end{array}$ & $\begin{array}{l}\text { Calcium } \\
\text { retention }{ }^{\mathrm{b}} \\
(\%)\end{array}$ & $\begin{array}{l}\text { Sodium } \\
\text { retention }{ }^{c} \\
(\%)\end{array}$ & $\begin{array}{l}\text { Average pore } \\
\text { radius }^{d}(\mathrm{~nm})\end{array}$ \\
\hline NF-270 & 13.5 & 55.0 & 5.5 & 43 & 40 & 0.42 \\
\hline NF-90 & 6.4 & 42.5 & 69.9 & 95 & 85 & 0.34 \\
\hline
\end{tabular}

${ }^{\mathrm{a}}$ Data from ${ }^{[22]}$ (measured on a $10 \mu \mathrm{m} \times 10 \mu \mathrm{m}$ area)

${ }^{\mathrm{b}}$ Experimental condition: $1 \mathrm{mM} \mathrm{CaCl}_{2}$ at 5 bar, $\mathrm{pH}=6$

${ }^{\mathrm{c}}$ Experimental condition: $10 \mathrm{mM} \mathrm{NaCl}$ at $5 \mathrm{bar}, \mathrm{pH}=6$

${ }^{\mathrm{d}}$ Data from ${ }^{[25]}$

\begin{tabular}{|l|c|c|c|c|c|}
\hline \multicolumn{6}{|c|}{ Table 2. Physicochemical parameters of the selected organic contaminants } \\
\hline \multicolumn{1}{|c|}{ Compound } & $\begin{array}{c}\text { Molecular weight } \\
(\mathrm{g} / \mathrm{mol})\end{array}$ & $\mathbf{p K}_{\mathbf{a}}$ & $\begin{array}{c}\text { Solubility in } \\
\text { water }(\mathrm{mg} / \mathrm{l})\end{array}$ & $\mathbf{L o g ~ K}_{\mathbf{0 w}}$ & $\begin{array}{c}\text { Dipole } \\
\text { moment } \\
\text { (Debye) }\end{array}$ \\
\hline Bisphenol A & 228 & $10.1^{\mathrm{a}}$ & $120^{\mathrm{b}}$ & $3.32^{\mathrm{e}}$ & $1.0^{\mathrm{e}}$ \\
\hline Tert-butyl Phenol & 150 & $10.2^{\mathrm{a}}$ & $700^{\mathrm{c}}$ & $3.31^{\mathrm{e}}$ & $1.0^{\mathrm{e}}$ \\
\hline Nonyl phenol & 220 & $10.3^{\mathrm{a}}$ & $5.0^{\mathrm{d}}$ & $5.77^{\mathrm{e}}$ & $1.4^{\mathrm{e}}$ \\
\hline
\end{tabular}

${ }^{a}$ Estimated using Pallas 3.0 software ${ }^{[43]}$

${ }^{\mathrm{b}} \operatorname{Ref}^{[9]}$

${ }^{c} \operatorname{Ref}^{[44]}$

${ }^{\mathrm{d}} \operatorname{Ref}{ }^{[45]}$

${ }^{\mathrm{e}}$ Estimated using Hyperchem 7.1 software ${ }^{[46]}$

\section{FIGURE CAPTIONS}

Figure 1: Molecular structure of the three hormone mimicking compounds used in this study

Figure 2: Permeate and feed concentrations of bisphenol A (BPA) as a function of filtration time for the (a) NF-270 and (b) NF-90 membranes. The feed solution contained approximately $500 \mu \mathrm{g} / \mathrm{L}$ of BPA in deionized water. Other experimental conditions were as follows: cross flow velocity $=$ $30.4 \mathrm{~cm} / \mathrm{s}$, permeate flux $=15 \mu \mathrm{m} / \mathrm{s}\left(54 \mathrm{~L} / \mathrm{m}^{2} \mathrm{~h}\right), \mathrm{pH}=6$, and temperature $=20.0^{\circ} \mathrm{C}$. The permeate and retentate were recirculated back to the feed reservoir during the nanofiltration run.

Figure 3: Permeate and feed concentrations of tert-butyl phenol (TBP) for the (a) NF-270 and (b) NF-90 membranes. The feed solution contained approximately $500 \mu \mathrm{g} / \mathrm{L}$ of TBP in deionized water. Other experimental conditions were as follows: cross flow velocity $=30.4 \mathrm{~cm} / \mathrm{s}$, permeate flux $=15 \mu \mathrm{m} / \mathrm{s}\left(54 \mathrm{~L} / \mathrm{m}^{2} \mathrm{~h}\right), \mathrm{pH}=6$, and temperature $=20.0^{\circ} \mathrm{C}$. The permeate and retentate were recirculated back to the feed reservoir during the nanofiltration run.

Figure 4: Feed concentrations of nonyl-phenol (NP) as a function of filtration time for the NF-90 and NF-270 membranes. The feed solution contained approximately $500 \mu \mathrm{g} / \mathrm{L}$ of NP in deionized water. Other experimental conditions were as follows: cross flow velocity $=30.4 \mathrm{~cm} / \mathrm{s}$, permeate flux $=15 \mu \mathrm{m} / \mathrm{s}\left(54 \mathrm{~L} / \mathrm{m}^{2} \mathrm{~h}\right), \mathrm{pH}=6$, and temperature $=20.0^{\circ} \mathrm{C}$. The permeate and retentate were recirculated back to the feed reservoir during the nanofiltration run.

Figure 5: The measured retentions of bisphenol A (BPA) and tert-butylphenol (TBP) (open symbols) as compared to model predictions (solid line, presented in our previous publication ${ }^{25]}$ ) for retention of non-adsorptive inert organics as a function of solute molecular weight by: (a) the NF-270 and (b) the NF-90 membranes. Retention measurements were taken the end of the filtration experiments (ca. 30 hours) at $\mathrm{pH} 6$, where these hormone mimicking compounds are neutral. Also included in the figure were measured retention of 4 natural hormones (solids symbols representing modeling were as follows: cross flow velocity $=30.4 \mathrm{~cm} / \mathrm{s}$, permeate flux $=15 \mu \mathrm{m} / \mathrm{s}\left(54 \mathrm{~L} / \mathrm{m}^{2} \mathrm{~h}\right)$, and temperature $=20.0^{\circ} \mathrm{C}$

Figure 6: Retention of bisphenol A (BPA) by the NF-270 membrane at two different $\mathrm{pH}$ as a function of time. The feed solution contained approximately $500 \mu \mathrm{g} / \mathrm{L}$ of BPA in deionized water Other experimental conditions were as follows: cross flow velocity $=30.4 \mathrm{~cm} / \mathrm{s}$, permeate flux $=15$ $\mu \mathrm{m} / \mathrm{s}\left(54 \mathrm{~L} / \mathrm{m}^{2} \mathrm{~h}\right)$, and temperature $=20.0^{\circ} \mathrm{C}$. The permeate and retentate were recirculated back to the feed reservoir during the nanofiltration run.

Figure 7: Effects of ionic strength on the retention of (a) bisphenol A (BPA) and (b) tert-butyl phenol (TBP) by the NF-270 membrane. The feed solution contained approximately $500 \mu \mathrm{g} / \mathrm{L}$ of the corresponding hormone mimicking compound in DI water or $50 \mathrm{mM} \mathrm{NaCl}$ solution. Other the corresponding hormone mimicking compound in DI water or $50 \mathrm{mM} \mathrm{NaCl}$ solution. Other
experimental conditions were as follows: cross flow velocity $=30.4 \mathrm{~cm} / \mathrm{s}$, permeate flux $=15 \mu \mathrm{m} / \mathrm{s}$ $\left(54 \mathrm{~L} / \mathrm{m}^{2} \mathrm{~h}\right), \mathrm{pH}=6$, and temperature $=20.0^{\circ} \mathrm{C}$. The permeate and retentate were recirculated back to the feed reservoir during the nanofiltration run.

Figure 8: Effects of natural organic matter (NOM) and ionic strength on the retention of (a) bisphenol A (BPA) and (b) tert-butylphenol (TBP) by the NF-270 membrane. The feed solution contained approximately $500 \mu \mathrm{L} / \mathrm{L}$ of the corresponding hormone mimicking compound in deionized water, deionized water plus $10 \mathrm{mg} / \mathrm{L}$ NOM, or $10 \mathrm{mM} \mathrm{NaCl}$ plus $10 \mathrm{mg} / \mathrm{L}$ NOM. Other experimental conditions were as follows: cross flow velocity $=30.4 \mathrm{~cm} / \mathrm{s}$, permeate flux $=15 \mu \mathrm{m} / \mathrm{s}$ $\left(54 \mathrm{~L} / \mathrm{m}^{2} \mathrm{~h}\right), \mathrm{pH}=6$, and temperature $=20.0^{\circ} \mathrm{C}$. The permeate and retentate were recirculated back to the feed reservoir during the nanofiltration run. 
Nghiem, D.L. ; Schäfer, A.I. ; Elimelech, M. (2005) Nanofiltration of hormone mimicking trace organic contaminants, Separation Science \& Technology, 40, 2633-2649.

DOI: $10.1080 / 01496390500283340$

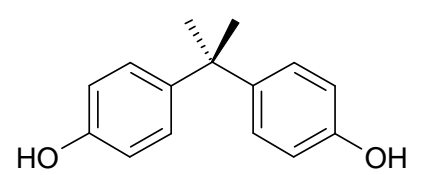

Bisphenol A (BPA)

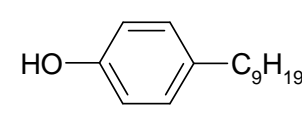

Nonylphenol (NP)
$\mathrm{HO}$

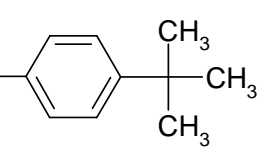

Tert-butylphenol (TBP)

FIGURE 1
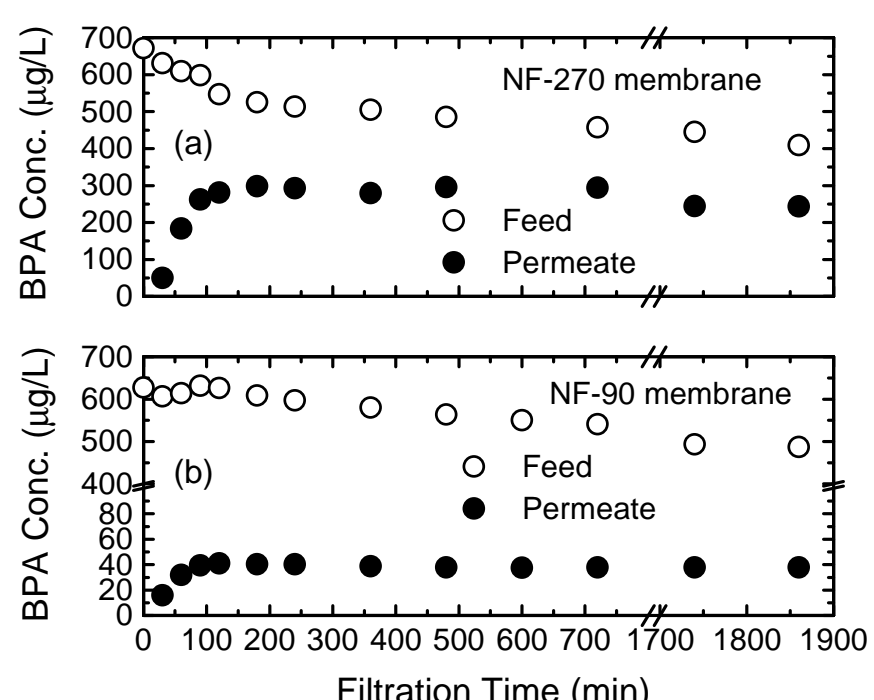

Filtration Time (min) 
Nghiem, D.L. ; Schäfer, A.I. ; Elimelech, M. (2005) Nanofiltration of hormone mimicking trace organic contaminants, Separation Science \& Technology, 40, 2633-2649.

DOI: 10.1080/01496390500283340
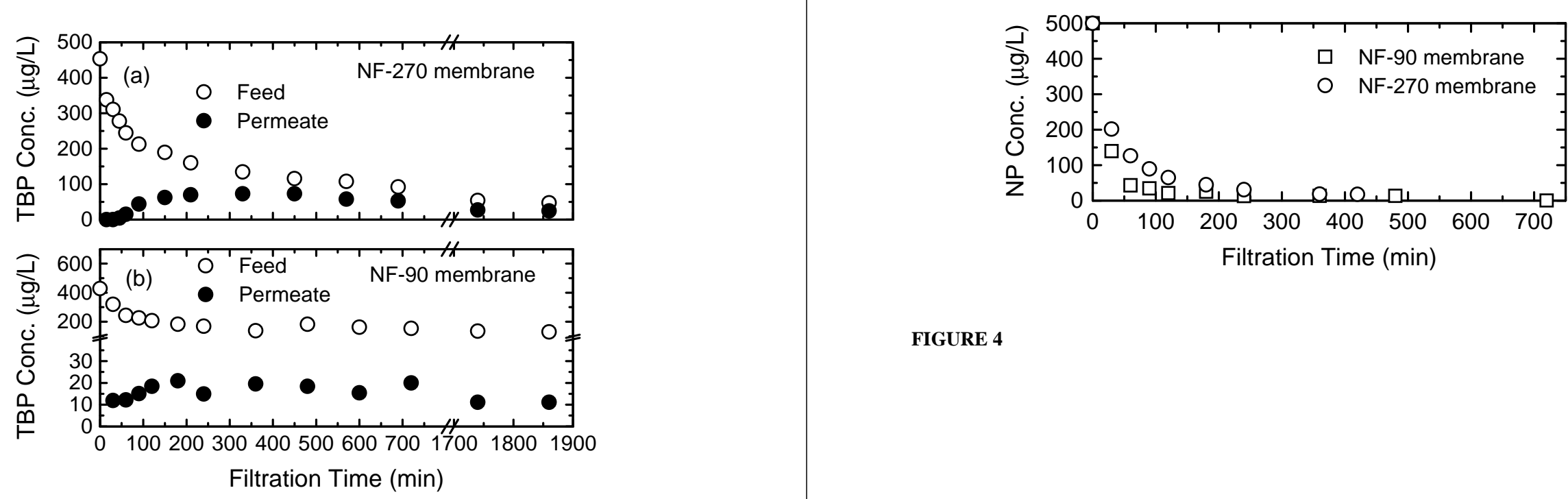

FIGURE 4

FIGURE 3 
Nghiem, D.L. ; Schäfer, A.I. ; Elimelech, M. (2005) Nanofiltration of hormone mimicking trace organic contaminants,

Separation Science \& Technology, 40, 2633-2649.

DOI: 10.1080/01496390500283340

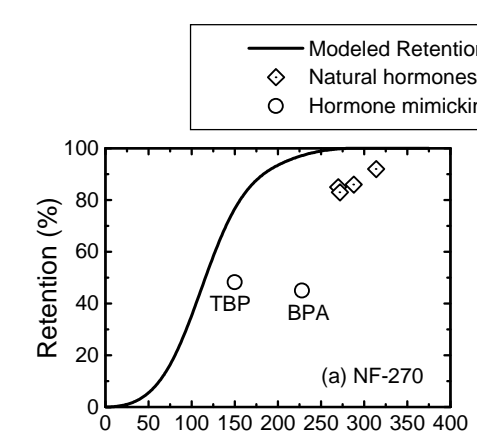

Solute MW $(\mathrm{g} / \mathrm{mol})$ (previous study)

(previous study)
g compounds (this study)

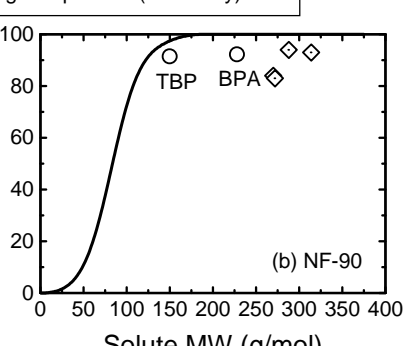

Solute MW $(\mathrm{g} / \mathrm{mol})$

FIGURE 5

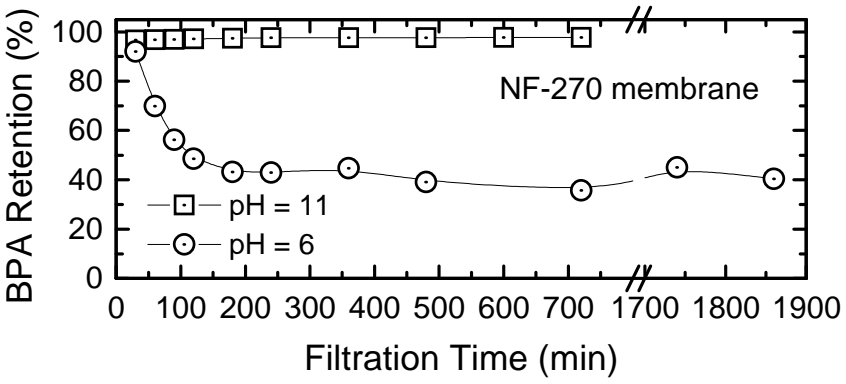

FIGURE 6 
Nghiem, D.L. ; Schäfer, A.I. ; Elimelech, M. (2005) Nanofiltration of hormone mimicking trace organic contaminants,

Separation Science \& Technology, 40, 2633-2649.

DOI: $10.1080 / 01496390500283340$
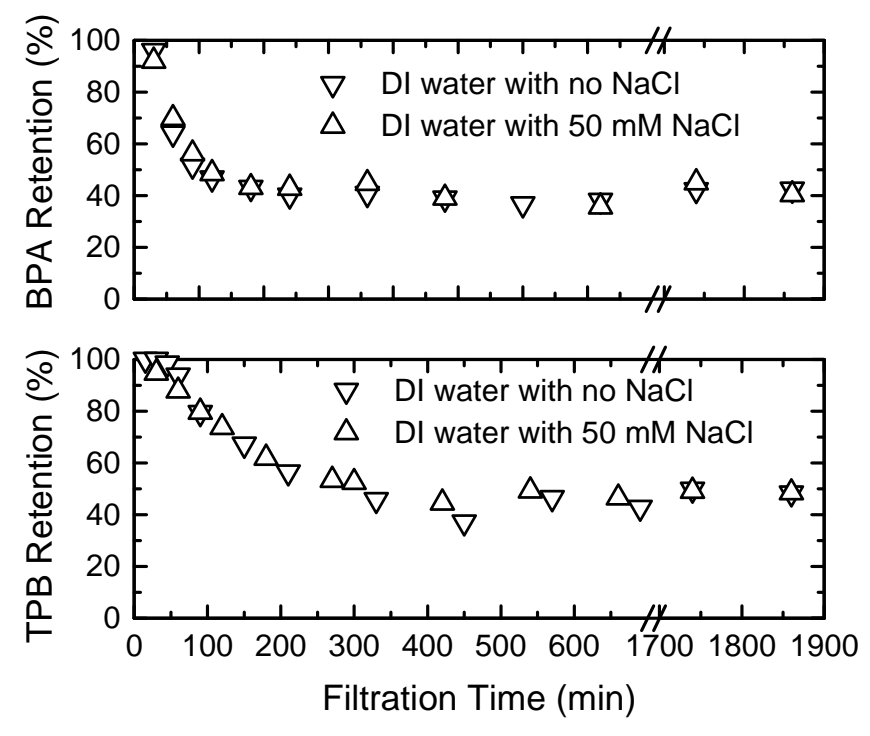

FIGURE 7

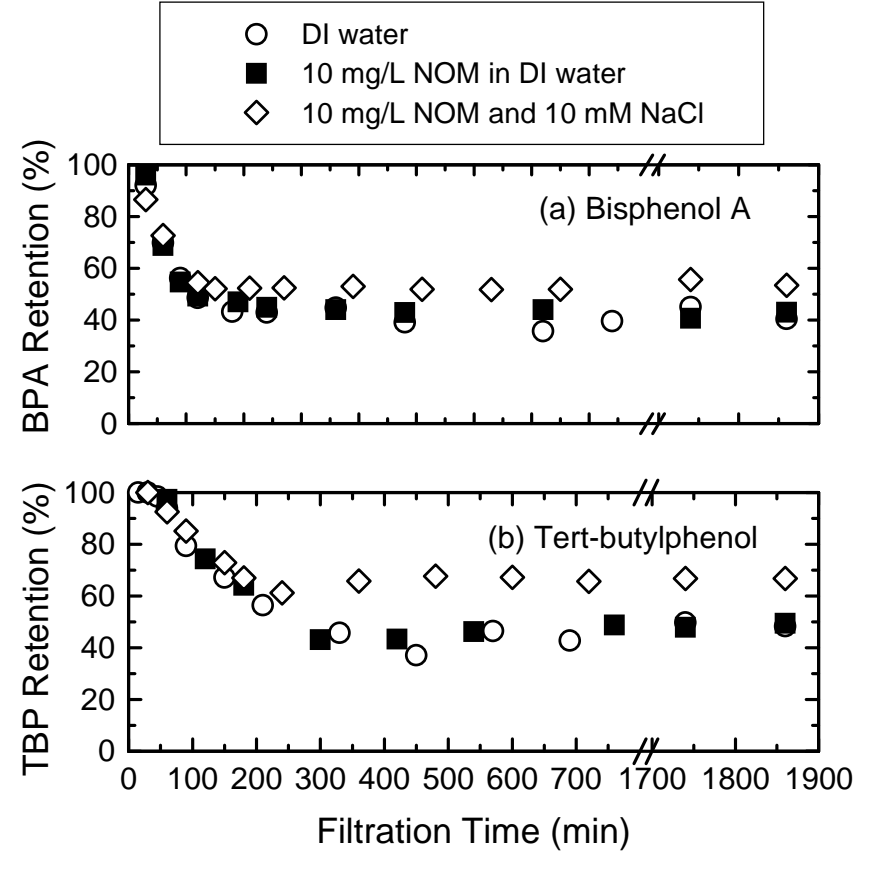

FIGURE 8 